\title{
Mitochondrial variability in the D-loop of four equine breeds shown by PCR-SSCP analysis
}

\author{
Patricia M. Mirol, P. Peral García and F.N. Dulout \\ Centro de Investigaciones en Genética Básica y Aplicada, Facultad de Ciencias Veterinarias, \\ Universidad Nacional de La Plata, La Plata, Argentina
}

\begin{abstract}
A fragment of 466 base pairs from a highly variable peripheral region of the mitochondrial D-loop of horses was amplified and analyzed by single stranded conformational polymorphism (SSCP). Fourteen distinct SSCP variants were detected in 100 horses belonging to four breeds (Arabian, ARB; Thoroughbred, TB; Argentinian Creole, ARC; and Peruvian Paso from Argentina, PPA). Each breed showed four to eight SSCP variants, many of which were shared between two or three of the studied breeds. Arabian horses were the most variable (eigth variants), with three variants unique to the breed. PPA and ARC showed two and one characteristic SSCP variants, respectively, while TB shared all its variants with at least one of the other breeds. An analysis based on the presence/absence of the variants revealed a closer relationship between PPA and TB, which was not completely unexpected considering the mixed ancestry of the PPA mares. The results also confirm the efficiency of SSCP to detect variability in horse mitochondrial DNA.
\end{abstract}

Key words: MTDNA, equine, PCR.

Received: March 24, 2000; accepted: March 15, 2002.

\section{Introduction}

Mammalian mitochondrial DNA (mtDNA) is maternally inherited, although rare events of paternal leakage have been reported (Kondo et al., 1990; Gyllensten et al., 1991; Avise, 1991; Kaneda et al., 1995). The rate of nucleotide substitution is 5 to 10 times higher in mtDNA compared to nuclear DNA (Brown et al., 1979). In humans, the substitution rate of the non-coding control region (D-loop) has been estimated to be 2.8 to 5 times higher than the rate for the rest of the mitochondrial genome (Aquadro and Greenberg, 1982); and within this region, the two peripheral domains (hypervariable region) evolve even faster (Pesole et al., 1999). Given the maternal transmission, the reported absence of recombination (Brown, 1985; Hagelberg et al., 1999) and the high substitution rate, mtDNA has proven to be a powerful tool in the analysis of intra- and interspecific variation, population structure and phylogeny. Recent reports have described mitochondrial D-loop variation in horses (Ishida et al., 1994a,b; 1995; Marklund et al., 1994; Dove et al., 1996; Bowling et al., 1998; Kavar et al., 1999). In this study we used SSCP

Send correspondence to P.M. Mirol, Centro de Investigaciones en Genética Basica y Aplicada, facultad de Ciencias veterinarias, universidad Nacional de La Plata, CC 296 (B1900AVW) La Plata, Argentina. E-mail: pmirol@fcv.medvet.unlp.edu.ar. analysis (Orita et al., 1989) of a peripheral region of the D-loop to estimate the variability and relationship among four horse breeds, Argentine Creole (ARC), Peruvian Paso from Argentina (PPA), Arabian (ARB) and Thoroughbred (TB). The Arabian horse is an ancient breed which originated on the Arabian Peninsula (Bailey and Lear, 1994; Andrade, 1954). The Thoroughbred breed originated in the United Kingdom from the crossbreeding of English mares of Tarpan ancestry with Arabian, Spanish, Turkish and Barb horses (Bailey and Lear, 1994). The origin of the Peruvian Paso can be traced to the 16th century, from Barb and Andalusian horses brought to Peru by Spanish conquerors. The Argentinean Creole horse constitutes a direct descendent of the Iberian horses of the 1500s, especially Andalusian, Spanish Pure Breed, Barb and Arabian (Cabrera, 1945).

In this report we analyze the variability of a fragment of the mitochondrial D-loop from four horse breeds to establish a preliminary pattern of variability prior to investigating sequence variation.

\section{Material and Methods}

The ARB, TB and ARC horses used in this study were traced back three maternal generations, and the PPA two generations. Total horse DNA was extracted from $500 \mu \mathrm{L}$ of blood with DNAzol (Gibco BRL) following the 
manufacturer's recommendations. The PCR primers used were 5'-AGGACTATCAAAGGAGAAGCTCTA-3' (D14991, Ishida et al., 1994a) and 5'-CCTGAaGTAGGAaCCAGATG-3' (H16498, Meyer et al., 1990), which amplify a 466 bp region situated between the tRNA ${ }^{\text {Thr }}$ (position 15397, Xu and Árnason, 1994) and the central domain of the D-loop (position 15863, Xu and Árnason, 1994). The horse D-loop contains four conserved blocks (CSB) and a region of direct eight base pair repeats (Xu and Árnason, 1994; Ishida et al., 1994a). The fragment amplified lies outside these blocks, and includes the most variable region of the D-loop (Ishida et al., 1994a). The $50 \mu \mathrm{L}$ reaction mix contained $100 \mathrm{ng}$ total horse DNA, $0.5 \mu \mathrm{M}$ of each primer, $0.1 \mathrm{mM}$ dNTPs and $2 \mathrm{U}$ Taq polymerase (Gibco BRL) in $20 \mathrm{mM}$ Tris- $\mathrm{HCl}$ (pH 8.4), $50 \mathrm{mM}$ $\mathrm{KCl}$ and $2 \mathrm{mM} \mathrm{MgCl}_{2}$, under mineral oil. The PCR consisted of a first denaturation step at $96{ }^{\circ} \mathrm{C}$ for two minutes followed by 35 one-minute cycles at $94{ }^{\circ} \mathrm{C}, 30 \mathrm{~s}$ at $55^{\circ} \mathrm{C}$ and one minute at $72{ }^{\circ} \mathrm{C}$, with an elongation step of $5 \mathrm{~min}$ at $72{ }^{\circ} \mathrm{C}$ in the last cycle. The size of the products was estimated by $1.5 \%$ agarose gel electrophoresis with pBR322 Msp I Digest as size marker.

Fifteen microliters of each PCR product were added to $40 \mu \mathrm{L}$ of LIS dye ( $10 \%$ sucrose, $0.01 \%$ bromophenol blue and $0.01 \%$ xylene cyanol FF; Maruya et al., 1996). The samples were then heated at $96^{\circ} \mathrm{C}$ for $10 \mathrm{~min}$, cooled on ice for at least $5 \mathrm{~min}$ and loaded onto a $10 \%$ polyacrylamide gel (491 acrylamide biacrylamide). Electrophoresis was carried out at $4{ }^{\circ} \mathrm{C}, 200 \mathrm{~V}$ in $0.5 \mathrm{x}$ TBE buffer for $18 \mathrm{~h}$. The gels were subsequently silver-stained, fixed in ethanol 5\%, stained with $\mathrm{AgNO}_{3} 0.2 \%$ and revealed with $2 \% \mathrm{CaCO}_{3}$.

A total of 100 horses were examined (45 ARC, 18 ARB, 30 PPA and 7 TB). The PCR products were of the same length, approximately 460 base pairs, which is in agreement with the published horse sequences (Ishida $e t$ al., 1994a).

\section{Results and Discussion}

SSCP analysis revealed 14 variants which were consistently obtained in different runs and in different SSCP conditions (Figure 1A). Heteroplasmy was not detected.
Table I shows the number of variants per breed, and indicates those patterns unique to each breed. ARC and PPA horses had five distinct SSCP patterns, TB had four and ARB horses had eight patterns. The high variability suggested by the existence of 14 different SSCP variants is also in agreement with the comparison of three sequences corresponding to the entire D-loop published by Ishida et al. (1994a), who found most of the substitutions (11 out of 18) within the fragment amplified in the present work. Our results are also similar to those of Marklund et al. (1994), who found 15 SSCP variants in a similar fragment of the D-loop corresponding to 78 horses from five Scandinavian breeds, each one of these showing between 5 and 10 variants. In a study of the same portion of the D-loop, Kavar et al. (1999) found three SSCP variants in 16 maternal lines of
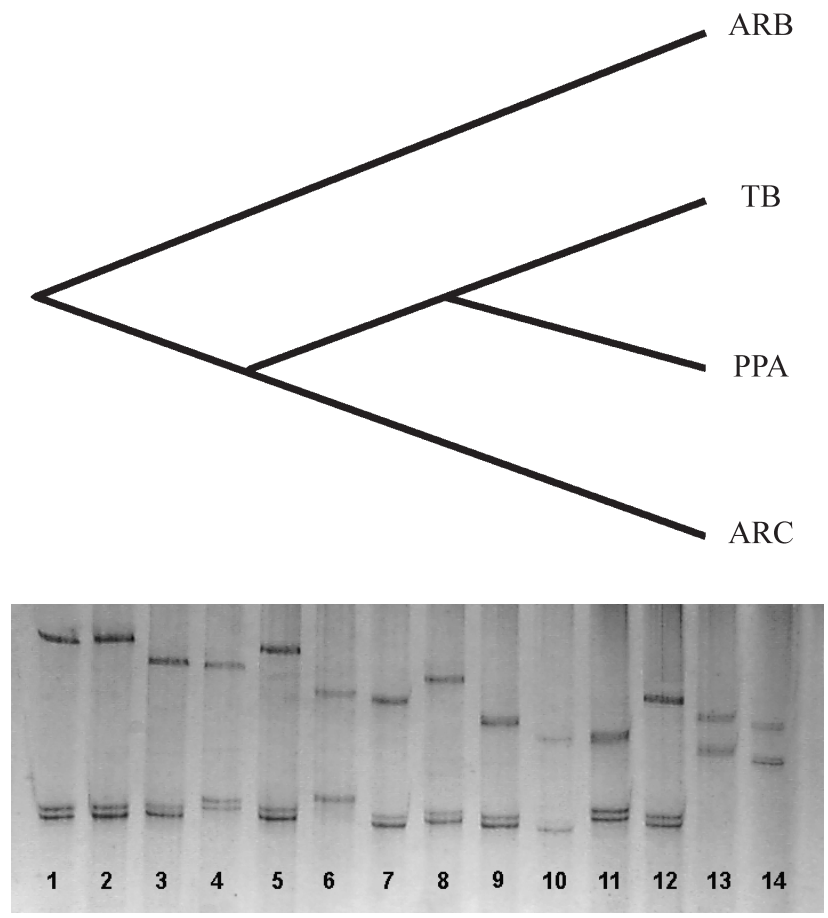

Figure 1 - A. Silver stained polyacrylamide gel showing the 14 SSCP variants detected in this study. B. Tree obtained with the Wagner parsimony method. ARC, Argentinean Creole; TB, Thoroughbred; PPA, Peruvian Paso from Argentina; ARB, Arabian.

Table I - Number and type of SSCP variants detected in each horse breed.

\begin{tabular}{|c|c|c|c|c|c|c|c|c|c|c|c|c|c|c|c|c|}
\hline \multirow[t]{2}{*}{ Breed } & \multirow[t]{2}{*}{$\mathrm{n}$} & \multirow[t]{2}{*}{$\mathrm{nV}$} & \multicolumn{14}{|c|}{ SSCP variant } \\
\hline & & & 1 & 2 & 3 & 4 & 5 & 6 & 7 & 8 & 9 & 10 & 11 & 12 & 13 & 14 \\
\hline $\mathrm{ARC}$ & 45 & 5 & - & 2 & 26 & - & - & - & - & - & 10 & - & 1 & 6 & - & - \\
\hline TB & 7 & 4 & - & - & 2 & - & - & - & - & 1 & - & - & - & 3 & - & 1 \\
\hline PPA & 30 & 5 & - & 5 & - & - & 12 & - & - & 6 & - & 1 & - & 6 & - & - \\
\hline $\mathrm{ARB}$ & 18 & 8 & 1 & 3 & - & 1 & - & 6 & 3 & - & 1 & - & - & - & 1 & 3 \\
\hline
\end{tabular}

ARC, Argentinean Creole; TB, Thoroughbred; PPA, Peruvian Paso from Argentina; ARB, Arabian. In bold, those variants that are unique for each breed. $\mathrm{n}=$ number of individuals.

$\mathrm{nV}=$ number of SSCP variants. 
the Lipizzan horse breed, which included 13 haplotypes. Furthermore, Bowling et al. (1998) found 28 base substitutions (corresponding to 22 haplotypes) in a study based on 398 bp of the D-loop from 43 Arabian horses. The results indicate a considerable degree of variation within the Arabian breed, which was found to be the most variable in our sample.

As it can be observed from Table I, Arabian and Peruvian Paso presented five and two characteristic patterns, respectively, not seen in the other breeds. Thoroughbred horses showed no characteristic pattern, and only one SSCP variant was found exclusively in Argentine Creole horses. Six SSCP variants were shared by the studied breeds, although none by the four breeds simultaneously. Each breed shared at least one variant with each one of the others. The most common variants in PPA (variant 5) or ARB (variant 6) were unique to those breeds, while the most common variants in ARC (variant 3) and TB (variant 12) were shared by TB and ARC and PPA, respectively.

A phenogram based on a discrete two-state character data matrix (0/1, 1/0; presence/absence of the SSCP variant or allele) using the Wagner parsimony method was constructed with the MIX program of the PHYLIP software package (Felsenstein, 1993). The tree (Figure 1B) shows a close relationship between PPA and TB with ARB as a more basal taxa followed by the Argentine Creole breed.

The interpretation of the results obtained is not straightforward. Arabian and TB are considered the foundation stock for many modern horse breeds (Bowling, 1994). They have probably contributed in varying degrees to the formation of American breeds. Arabian and Barbs were brought to America by the Spanish conquerors along with horses such as the Spanish Pure Breed and the Andalusian. Their ancestry to South American breeds has been suggested by blood group and polymorphic protein loci analyses (De Andrés Cara, 1982; Rodriguez-Gallardo et al., 1992). A correlation between some of these races based on five polymorphic protein loci (Peral-García et al., 1996) resulted in similar values between the ARC, Andalusian and PP from Peru. However, the Argentinean Peruvian Paso is a breed in formation and, therefore, even when stallions are brought from Peruvian Paso in Peru, the mares are frequently not pure PP. Their position on the tree in Figure $1 \mathrm{~B}$ may be explained by the fact that the maternal history is followed through the mtDNA, which is probably of mixed ancestry. On the other hand, the position of the ARC breed, a well established breed in Argentina, in Figure 1B is not clear, although it is well differentiated from the other breeds examined. We must note here that this unclear position could be related to the missing information about the ancestral breeds of the analyzed samples.

The reliability of these results lies fundamentally on the assumption that each SSCP variant corresponds to a different haplotype. It is generally accepted that SSCP can detect even single base substitutions (Takeda et al., 1995;
Ostellari et al., 1996). The resolution power of this method is crucially dependent on the fragment examined and on the conditions of the experiment (temperature, gel concentration, run length). Under different experimental conditions, we have always obtained the same patterns. If some point mutations did not produce a new variant, the variability would be underestimated and the results would represent a first approximation to the relationship and variability of the analyzed breeds. In conclusion, SSCP allowed the detection of extensive variability in PPA, ARC, TB and ARB horse breeds, which makes this technique a valuable first step in future phylogenetic studies, including sequencing techniques.

\section{Acknowledgements}

This work was supported by National Research Council (CONICET) and Universidad de la Plata grants to P.P.G. and F.N.D., and SECyT grant to P.M.M. The authors wish also thank Mariana Kienast for collecting the samples and David Bilton for useful comments.

\section{References}

Andrade R (1954) Alrededor del Caballo Español. Ed. Sociedad de Astoria, Lisboa.

Aquadro CF and Greenberg BD (1982) Human mitochondrial DNA variation and evolution: analysis of nucleotide sequences from seven individuals. Genetics 103:287-312.

Avise JC (1991) Matriarchal liberation. Nature 352:192.

Bailey E and Lear TL (1994) Comparison of Thoroughbred and Arabian horses using RAPD markers. Anim. Genet. 25 (Suppl. 1):105-108.

Bowling AT (1994) Population genetics of Great Basin feral horses. Anim. Genet. 25:67-74.

Bowling AT, Del Valle A and Bowling M (1998) Mitochondrial D-loop DNA sequence variation among Arabian horses. Anim. Genet. 29 (Suppl. 1):17.

Brown WM (1985) The mitochondrial genome of animals. In: MacIntyre RJ (ed) Molecular Evolutionary Genetics. Plenum, New York, pp. 95-130.

Brown WM, George, M. Jr. and Wilson AC (1979) Rapid evolution of animal mitochondrial DNA. Proc. Natl. Acad. Sci. USA 76:1967-1971.

Cabrera A (1945) Caballos de América. Ed. Sudamericana, Buenos Aires, pp. 17-18.

De Andrés Cara DF (1982) Pura raza Española de caballo. Comparación con otras razas mediante sus polimorfismos enzimáticos sanguíneos. Doctoral thesis, Universidad de Cordoba, España.

Dove P, Kavar T and Habe F (1996) Mitochondrial D-loop variation in Lipizzan horses. Anim. Genet. 27 (Suppl.2):33.

Felsenstein J (1991) PHYLIP (Phylogeny Inference Package), Version 3.4. University of Washington, Seattle. http:// (Autor completar).

Gyllensten UB, Wharton D, Josefsson A and Wilson AC (1991) Paternal inheritance of mitochondrial DNA in mice. Nature 352:255-257.

Hagelberg E, Goldman N, Lió P, Whelan S, Schiefenhövel W, Clegg JB and Bowden DK (1999) Evidence for mitochon- 
drial DNA recombination in a human population of island Melanesia. Proc.R. Soc. Lond. B 266:485-492.

Ishida N, Hasegawa T, Takeda K, Sakagami M, Onishi A, Inumaru S, Kamtsu M and Mukoyama H (1994a) Polymorphic sequence in the D-loop region of equine mitochondrial DNA. Anim. Genet. 25:215-221.

Ishida N, Hirano T and Mukoyama H (1994b) Detection of aberrant alleles in the D-loop region of equine mitochondrial DNA by single-strand conformation polymorphism (SSCP) analysis. Anim. Genet. 25:287.

Ishida N, Oyunsuren T, Mashima S, Mukoyama H and Saitou N (1995) Mitochondrial DNA sequences of various species of the genus Equus with special reference to the phylogenetic relationship between Przewalskiis wild horse and domestic horse. J. Mol. Evol. 41:180-188.

Kaneda H, Hayashi J, Takahama S, Taya C, Lindahl KF and Yonekawa H (1995) Elimination of paternal mtDNA in istraspecific crosses during early mouse embryogenesis. Proc. Natl. Acad. Sci. USA 92:4542-4546.

Kavar T, Habe F, Brem G. and Dove P (1999) Mitochondrial D-loop sequence variation among the 16 maternal lines of the Lipizzan horse breed. Anim. Genet. 30:423-430.

Kondo R, Satta Y, Matsuura ET, Ishiwa H, Takahata N and Chigusa SI (1990) Incomplete maternal transmission of mitochondrial DNA in Drosophila. Genet. 12:657-663.

Marklund S, Chaudhary R, Marklund L, Sandberg K and Andersson L (1994) Extensive mtDNA diversity in horses revealed by PCR-SSCP analysis. Anim. Genet. 26:193-196.

Maruya E, Saji H and Yokoyama S (1996) PCR-LIS-SSCP (low ionic strength stranded conformation polymorphism) - a simple method for high resolution allele typing of HLA-DQB1 and DPB1. Genome Res. 6:51-57.
Meyer A, Kocher TD, Basasiwaki P and Wilson AC (1990) Monophyletic origin of Lake Victoria cichlid fishes suggested by mitochondrial DNA sequences. Nature 347:550-553.

Orita M, Iwahana H, Kanazawa H, Hayashi $H$ and Sekiya $T$ (1989) Detection of polymorphisms of human DNA by gel electrophoresis as single strand conformation polymorphisms. Proc. Natl. Acad. Sci. USA 86:2766-2770.

Ostellari L, Bargelloni L, Penzo E, Patarnello, P and Patarnello T (1996) Optimization of single-strand conformation polymorphism and sequence analysis of the mitochondrial control region in Pagellus bogarevo (Sparidae, Teleostei): rationalized tools in fish population biology. Anim. Genet. 27:423-427.

Peral-García P, Kienast M, Villegas E, Díaz S and Dulout F (1996) Estudio de relaciones genéticas entre razas equinas mediante el análisis multivariado. Agro Sur 24:39-47.

Pesole G, Gissi C, De Chirico A and Saccone C (1999) Nucleotide substitution rate of mammalian mitochondrial genomes. J. Mol. Evol. 48:427-434.

Rodriguez-Gallardo PP, Aguilar P, Vega JL and de Andrés DF (1992) Blood group and polymorphism gene frequences for the Andalusian horse breed. A comparison with four American Horse breeds. Arch. Zootecnia 41:433-42

Takeda K, Onishi A, Ishida N, Kawakami K, Komatsu M and Inumaru S (1995). SSCP analysis of pig mitochondrial DNA D-loop region polymorphism. Anim. Genet.26: 321-326.

Xu X, and Árnason U (1994) The complete mitochondrial DNA sequence of the horse, Equus caballus: extensive heteroplasmy of the control region. Gene 148:357-362. 